\title{
O direito à memória: a luta pela legitimação e visibilidade das intelectuais negras na sociedade de Pernambuco
}

Jacqueline Martins

\section{Resumo}

Os valores e a ideologia racista e sexista predominantes na sociedade pernambucana buscam ofuscar, invisibilizar e negar a identidade da mulher negra e sua participação intelectual, política, social e histórica na formação dessa sociedade. Nesse sentido, o trabalho apresentado tem como objetivo apontar reflexões em relação à história da trajetória e das produções intelectuais das mulheres negras no estado de Pernambuco, buscando, assim, contribuir para uma legitimação de tal intelectualidade; propõe, ainda, contribuir na reflexão sobre uma noção de justiça reposicionada pelo reconhecimento do aporte intelectual e do protagonismo das mulheres negras no processo de construção da sociedade pernambucana, por meio da cultura como elemento proporcionador do direito à memória. Com a licença que foi dada, eis a palavra pensada! Palavras-chave: Gênero - Raça - Intelectualidade. 


\section{Introdução}

Conforme Elisa Larkin Nascimento (2003, p. 23), o silêncio constitui um dos pilares da dominação, bem como invisibilizar o afrodescendente constitui uma forma de racismo.

$\mathrm{Na}$ acepção popular, racista é quem fala do racismo ou enuncia a identidade do discriminado; a atitude não-racista é o silêncio. Contudo, verifica-se que tal noção representa não apenas um equívoco com um dos pilares que sustentam a dominação, pois o silêncio configura uma das formas mais eficazes de operação do próprio racismo no Brasil. Complemento do silêncio, outra forma e sintoma do racismo está no processo de tornar invisível a presença do afrodescendente na qualidade de ator, criador e transformador da história e da cultura nacional (NASCIMENTO, 2003, p. 23).

Partindo dessa premissa, observamos a atuação do racismo e do sexismo sobre a acepção de ser mulher negra, como sujeito político de sua própria história e como agente de produção intelectual. Quando a sociedade pensa em pessoas intelectuais, logo no imaginário social se formata a ideia de um sujeito que proporcionou uma forte intervenção cultural, de talento memorável nas artes, universalmente celebrado no mundo acadêmico ou em qualquer outra esfera social. Associada a esses estereótipos de intelectuais, está a construção ideológica de quem são os possíveis sujeitos a compor esses espaços de intelectualidade.

Para permitir melhor compreensão da temática, recorremos às concepções de Antônio Gramsci. Diversamente da concepção do determinismo estereotipado de quem é, ou melhor, de quem pode ser um intelectual, Gramsci elabora um conceito inovador denominado "intelectuais orgânicos". Os intelectuais tradicionais, que se mantinham alheios à dinâmica das transformações sociais, para ele eram os eclesiásticos, os funcionários dotados de habilidades técnicas e os acadêmicos. Podemos considerar que esses intelectuais tradicionais, tendo em vista a força do capitalismo que identifica os indivíduos pela capacidade de acumulação de capital, são os intelectuais hegemônicos, estando inseridos em espaços sociais onde podem construir e manipular ideias para a manutenção do poder.

Esses sujeitos, intelectuais tradicionais, estavam voltados para a manutenção de um status quo que privilegiava os estratos sociais de seu interesse, desqualificando as construções intelectuais daqueles que não eram detentores de poder econômico, muito menos de status social e que, logo, não eram 
considerados intelectuais, por se considerar que eram incapazes de produzir com a mente. Já essa nova designação de intelectuais, chamados de orgânicos por Gramsci, faz parte de um organismo vivo e em expansão; trata dos indivíduos que estão em conexão com o mundo do trabalho, com a política, com a cultura desenvolvida pelo seu grupo social, transcendendo a ideia de intelectuais ligados ao simples exercício de uma profissão ou produção acadêmica.

Para Gramsci, todos os seres humanos são considerados intelectuais, pois cada um pode promover novas construções de pensamento e novas concepções de mundo a partir da perspectiva do grupo social em que está inserido:

Todos os homens são intelectuais, poder-se-ia dizer então: mas nem todos os homens desempenham a função de intelectuais. Quando se distingue entre intelectuais e não-intelectuais, faz-se referência, na realidade, tão somente à imediata função social da categoria profissional dos intelectuais, isto é, leva- se em conta a direção sobre o peso maior da atividade profissional específica, se na elaboração intelectual ou se no esforço muscular-nervoso. Isto significa que, se se pode falar de intelectuais, é impossível falar de não-intelectuais, porque não existem não-intelectuais. Mas a própria relação entre o esforço de elaboração intelectual-cerebral e esforço muscular-nervoso não é sempre igual; por isso existem graus de atividade específica intelectual. Não existe atividade humana da qual se possa excluir toda intervenção intelectual, não se pode separar o homo faber do homo sapiens. Em suma, todo homem, fora de sua profissão, desenvolve uma atividade intelectual qualquer, ou seja, é um "filósofo", um artista, um homem de gosto, participa de uma concepção do mundo, possui uma linha de conduta moral, contribui assim para manter ou para modificar uma concepção do mundo, isto é, para promover novas maneiras de pensar (GRAMSGI, I982, p. 6).

Contrapondo as ideias de Gramsci no tocante aos sujeitos que podem ser considerados intelectuais em nossa sociedade, há uma construção do perfil dos intelectuais que consiste, geralmente, em sujeitos do sexo masculino, brancos e alocados em classes econômicas mais altas. É a partir da construção desse perfil que se nega o desenvolvimento e a contribuição do trabalho intelectual das mulheres, principalmente das mulheres negras, e também as construções intelectuais desenvolvidas nos estratos sociais mais baixos. Percebemos que existe uma elitização e um domínio do patriarcado no âmbito da intelectualidade, um padrão hegemônico de intelectuais que interdita outras formas de produção e de ser intelectual. Conforme ressalta bell 
hooks ${ }^{\mathrm{I}}$, é o conceito excludente de intelectualidade fundada no racismo e no sexismo:

E o conceito ocidental sexista/racista de quem e o que um intelectual que elimina a possibilidade de nos lembrarmos de negras como representativas de uma vocação intelectual. Na verdade, dentro do patriarcado capitalista com a supremacia branca, toda a cultura atua para negar às mulheres a oportunidade de seguir uma vida da mente, e torna o domínio intelectual um lugar "interdito" (HOOKS, I995, p. 468).

Nessa esteira, realizamos a reflexão sobre a invisibilidade das intelectuais negras - das trincheiras do confronto aos estigmas nelas colocados pelo racismo.

A ponderação de Gramsci acerca dos intelectuais orgânicos possibilita enxergarmos as mulheres negras e todo o leque de produção intelectual desenvolvida por elas, para conceber uma concepção de mundo contra-hegemônico na sociedade brasileira, em oposição à concepção que contém os "intelectuais tradicionais" que desenvolveram produções literárias que fundamentam e confirmam o mito da democracia racial $^{2}$, suavizando o período escravocrata ${ }^{3}$, disseminando uma falsa ideia de que a transição desse período para o de pós-abolição ocorreu sem traumas para a população negra. Essa dissimulação histórica, criada por uma gama de intelectuais, romantizou o período escravocrata, quando as mulheres negras foram massacradas, tendo negadas as suas identidades, tornando-se alvo de abusos morais e sexuais e demais violências promovidas pelos senhores brancos, pois o corpo feminino deveria servir ao homem branco, detentor de recursos financeiros e de poder político. É impe-

I Gloria Jean Watkins, mais conhecida pelo pseudônimo bell hooks - escritora e ativista social. O apelido "bell hooks", que ela escolheu para assinar suas obras, é uma homenagem aos sobrenomes da mãe e da avó. O nome é grafado assim mesmo, em letras minúsculas. A justificativa se acha na frase da própria bell: "o mais importante em meus livros é a substância e não quem sou eu" (HOOKS, 2009). Para ela, nomes, títulos, nada disso tem tanto valor quanto as ideias. E, por respeito à opção da autora, decidiu-se manter a grafia com que ela se identifica.

2 O uso da expressão "mito da democracia racial", ainda que passível de discussões, no texto deve ser compreendido como discurso que distorce o padrão das relações raciais no Brasil, construído ideologicamente por uma elite considerada branca, intencional ou voluntariamente, para maquiar a opressiva distinção entre negros e brancos.

3 Compreende-se período escravocrata como um lapso temporal na história do Brasil que vai desde o Brasil Colônia até o fim do Império com a promulgação da Lei Áurea em I888; no sistema de produção desse período, além de a mão de obra não ser remunerada, o indivíduo (o escravo) é propriedade de outro, podendo ser vendido, doado, emprestado, alugado, hipotecado. Não existem registros precisos dos primeiros escravos negros que chegaram ao Brasil. A tese mais aceita é a de que, em I538, Jorge Lopes Bixorda, arrendatário de pau-brasil, teria traficado para a Bahia os primeiros escravos africanos. 
rioso salientar que durante o referido período existiram mulheres negras que empreenderam resistência à imposição da concepção ocidental, reagindo contra o sistema de escravidão. Dentre elas, destaca-se Dandara, esposa de Zumbi, que como ele lutou com armas pela libertação total das negras e dos negros no Brasil; também rememoramos Luiza Mahin, uma das líderes da maior revolta escrava ocorrida no Brasil - o Levante dos Malês -, pela participação em inúmeras revoltas de escravos ocorridas em Salvador nos anos de I830.

Os afrodescendentes, já estigmatizados pela historiografia tradicional, a qual propagava que a África era um continente onde não houve civilização avançada, muito menos um sistema complexo de filosofia, ciência e metafísica, ou seja, um continente sem história - tese que posteriormente sofreu abalos pelos contrapontos das pesquisas e estudos do historiador, egiptólogo, antropólogo e físico Cheick Anta Diop -, carregam também o legado dos estigmas do racismo de que os negros e as negras são sujeitos incapazes de produção intelectual. Dentre esses estigmas, a mulher negra, no estado de maior vulnerabilidade, é estigmatizada como aquela que tem utilidade exclusiva para servir aos outros; é chamada "ama de leite" ou "mucama", é vista como objeto de satisfação sexual para os homens brancos, a chamada "deusa mulata" -, mulheres que só têm corpos e não mentes. Essa aceitação cultural da forma como a mulher negra é vista persiste até os dias atuais.

\section{II. $O$ gênero, a negritude e a intelectualidade}

Diante do exposto, é imperioso destacar que as mulheres negras não permaneceram omissas, passivas ou inertes diante desse manto da invisibilidade e negação da mulher negra como sujeito intelectual. É a partir da produção orgânica da periferia, da sabedoria de mães de favela e de seus esforços para a manutenção da cultura popular negra que se torna possível compreender a produção intelectual das mulheres negras para o confronto aos estigmas produzidos pela intelectualidade tradicional e a luta pela legitimação de suas produções como intelectuais. Observamos o mesmo confronto para essa legitimação com as mulheres negras acadêmicas; não é por coincidência que a maioria delas saiu das periferias para os espaços considerados intelectuais, como as faculdades e universidades.

Mediante esse prisma de produção intelectual orgânica da periferia, fazemos referência à obra de escritora mineira Carolina Maria de Jesus ${ }^{4}$. Sua mais

4 Além de Quarto de despejo (I960), merecem ser destacadas outras obras de Carolina Maria de Jesus, 
expoente obra, Quarto de despejo (I960), retrata o cotidiano cruel dos favelados de sua época: ela dividia seu tempo entre catar lixo para conseguir comida para ela e seus três filhos, e ler e escrever seu diário todas as noites antes de dormir. Pelo olhar dessa mulher nós enxergamos um dos lados mais cruéis do racismo: a miséria, a fome, as mazelas e a luta pela sobrevivência de uma fatia da população periférica.

Com linguagem simples, destoante da típica linguagem erudita dos grandes literatos, Carolina Maria de Jesus consegue, com estilo peculiar, realismo e sensibilidade, pensar e escrever sobre os acontecimentos ao seu redor, refletindo sobre os problemas sociais e os dramas humanos e fazendo denúncias sociopolíticas em seus escritos contra uma cultura que privilegia alguns e exclui a maioria, ou seja, a população negra e pobre. Uma mulher que frequentou a escola por apenas um pouco mais de dois anos, negra, catadora de lixo, mãe solteira, consegue em um contexto todo adverso pensar dialeticamente sobre a sociedade e escrever uma das maiores obras de referência para estudos culturais fora e dentro do Brasil. Ela é exatamente o que a grande parte da sociedade não pensa que ela é, ou seja, uma intelectual. Pelo simples fato de Garolina Maria de Jesus não preencher os requisitos impostos para preencher o status de intelectual no Brasil, ela não é celebrada no país como tal; mesmo tendo escrito mais quatro obras, tem-se, ainda, um olhar de desdém aos seus escritos por parte de muitos literatos.

É a ideologia do racismo produzido pela hegemonia de intelectuais, que se sentem ameaçados pela intelectualidade de uma mulher negra e pobre, que transcende o lugar reservado para ela na sociedade como "mãe preta", "deusa mulata" ou "catadora de lixo". Pois, mesmo não tendo a educação escolar tradicionalmente exigida, Carolina Maria de Jesus consegue compreender e expressar com maestria as patologias sociais; isso abala a cultura hegemônica do país de sua época. A despeito dos mais de 50 anos da publicação de Quarto de despejo, ao fazermos a leitura da citada obra percebemos a mesma contundente realidade demonstrada no livro nos dias atuais. Enxergamos os vários quartos de despejo espalhados por todo Brasil, o que eterniza a obra, seus escritos, sua genialidade e as memórias da negra mulher intelectual Carolina Maria de Jesus.

...Não sei dormir sem ler. Gosto de manusear um livro. O livro é a melhor invenção do homem (...) Era o Seu João. Perguntou-me onde encontrar folhas 
de batatas para sua filha bochechar um dente. Eu disse que na Portuguesinha era possível encontrar. Quiz saber o que eu escrevia. Eu disse ser o meu diário. Nunca vi uma preta gostar tanto de ler livros como você. Todo mundo tem um ideal. O meu é gostar de ler (JESUS, 2006, p. 23). ${ }^{5}$

Pelos poucos relatos que fazem menção sobre sua vida e obra, o que se sabe é que, após a publicação do livro, Carolina Maria de Jesus ganhou fama efêmera e também algum dinheiro, apenas o suficiente para retirá-la da favela, mas não da pobreza. E é aqui que observamos a demonstração do desprezo dado à produção intelectual dessa mulher negra: o universo intelectual tradicional permitiu que sua obra e personalidade caíssem na invisibilidade. Ela morre em I4 de agosto de I977 num pequeno sítio na periferia de São Paulo, esquecida pelo público e pela imprensa e negada pelo racismo.

Outras mulheres emergem na sociedade brasileira e se destacam em todo o território nacional, com intensa atividade na vida universitária, e nos é oportuno citar seus nomes: Lélia Gonzalez, Beatriz Nascimento, Sueli Carneiro, Vera Baroni, Inaldete Pinheiro, dentre outras; foram/são mulheres que se tornaram pesquisadoras, intelectuais, e romperam com esse processo de invisibilidade dentro da Academia ${ }^{6}$.

\section{As muitas outras Carolinas}

Fazendo uso do conceito de intelectuais orgânicos de Gramsci, podemos pensar que estes têm íntima relação com a cultura, a história, a política, a manutenção e a prática de saberes tradicionais ${ }^{7}$, e se organizam para propor mudanças na sociedade. Por esse prisma, é possível reconhecer como trabalho intelectual as diversas contribuições das mulheres negras para manutenção das tradições e da cultura negra no estado de Pernambuco. Em virtude da negação

5 Texto transcrito sem adaptações à gramática normativa, conforme o original. Carolina Maria de Jesus se afirmava mãe solteira por opção, pois nenhum homem admitia dormir ao lado de uma mulher que tinha lápis e papel ao lado do travesseiro.

6 O vocábulo "Academia" utilizado refere-se a instituições destinadas a ensino, pesquisa e extensão e que promovem atividades científicas, literárias e artísticas, tais como as universidades.

7 Como saberes tradicionais, leia-se todo saber produzido por grupos humanos culturalmente diferenciados que historicamente reproduzem seu modo de vida, de forma mais ou menos isolada, com base em modos de cooperação social e formas específicas de relações com a natureza, caracterizados tradicionalmente pelo manejo sustentável do meio ambiente. Assim, as religiões de matriz africana estão inseridas no segmento de "povos tradicionais". 
do racismo, faz-se necessária a visibilização e legitimação das produções como obras de verdadeiras intelectuais orgânicas.

Entre essas intelectuais, no âmbito da cultura, destaca-se Maria Madelena Correia do Nascimento, conhecida mundialmente como Lia de Itamaracá ${ }^{8}$; é considerada uma lenda viva do estado, colabora com Pernambuco por suas cirandas e seus cocos e pelo Espaço Cultural Estrela de Lia, no qual desenvolve atividades educativas com crianças e adolescentes em Itamaracá, realizando oficinas com abordagem da identidade negra, da percussão, da representação da pessoa negra na sociedade brasileira, da estética negra e do estilismo. Lia de Itamaracá tem sido um esteio para muitas mulheres negras garantirem a sua subsistência por meio da arte, pois a partir da representatividade de seu trabalho no campo cultural tem dado oportunidade para muitas outras mulheres negras disponibilizarem suas contribuições a Pernambuco.

Ainda no trabalho de fomento à cultura negra, o coco de roda da comunidade Amaro Branco, antiga colônia de pescadores da cidade de Olinda, no estado de Pernambuco, conta com a atuação de Maria da Glória Braz de Almeida, mais conhecida como Dona Glorinha ${ }^{9}$, e de Dona Maria do Monte ${ }^{10}$, mais conhecida como Dona Montinha. Ambas são mestras do samba africano que é realizado anualmente no bairro do Amaro Branco e que atua nessa comunidade como instrumento de educação preventiva para jovens e crianças, contra o tráfico de drogas e o abuso sexual, além de promover a manutenção e a transferência do legado cultural para esses sujeitos.

Além delas, ainda no estado de Pernambuco, Dona Maria Césia de Anunciação, também conhecida como Rainha Mariú, viveu dentro do Maracatu Es-

8 Lia de Itamaracá: seu nome está atrelado ao lugar onde nasceu e vive; é cantora, compositora e dançarina de ciranda pernambucana. Tornou-se referência nacional e internacional no que tange ao tema ciranda e à cultura popular. Em 2004, foi agraciada com a Ordem do Mérito Cultural, premiação concedida pelo Ministério da Cultura a personalidades brasileiras e estrangeiras que são reconhecidas por suas contribuições à cultura do Brasil.

9 Mais antiga mestra das sambadas de coco do Amaro Branco, conhecida como "A Dama do Coco de Amaro Branco", a cantora e compositora de coco em Pernambuco é considerada memória viva do coco no bairro. Os primeiros sambas (cocos) aprendeu com sua mãe, Maria Belém, também conquista de muita tradição, que foi filha de uma escrava fugida chamada Joana Belém, que lhe ensinou o coco que aprendeu na senzala. Dona Glorinha também é presidente do Bloco do Pescador, que desfila pelo bairro Amaro Branco no carnaval.

Io Filha de pescador, também cresceu cantando nas rodas do Amaro Branco. Após uma longa pausa em virtude de problemas de saúde, voltou ao coco de roda com toda motivação nos anos 2000 . Mas voltou a ter complicações na saúde, vindo a falecer em outubro de 20I5. Em seu velório, para homenageá-la, os jovens e todos os outros membros da comunidade realizaram um cortejo em que catavam os cocos de sua composição - esse cortejo teve início na sua casa e terminou no cemitério onde foi sepultada. 
trela Brilhante da cidade de Igarassu. A matriarca do Estrela Brilhante começou a dançar maracatu ainda menina - aos I2 anos de idade - e, desde então, a dança passou a fazer parte de sua vida; faleceu em 2003 com IO4 anos. Sua vida e seu trabalho para manutenção da tradição do maracatu são referência para a juventude negra no estado, principalmente para aqueles que lutam pela expansão e divulgação do maracatu. Na mesma estirpe, a senhora Maria Júlia do Nascimento, conhecida como a Rainha Dona Santa, nascida em 24 de março de $\mathrm{I} 877$, foi a primeira rainha do maracatu a ser coroada em uma igreja católica: ela ampliou a visibilidade dos maracatus como expressão da cultura e da resistência negras.

Toda manifestação da arte e da cultura negra empreendida por essas mulheres é resultado de labor intelectual, que tem o claro propósito de manutenção de tradições que são traduzidas como expressões vivas do trabalho coletivo e da responsabilidade com a promoção da cidadania para a população negra.

É imperioso destacar também a manutenção de saberes tradicionais, por meio da religiosidade afro-brasileira e do protagonismo de muitas Iyalorixás negras ${ }^{\mathrm{II}}$, para a sua preservação, e como elas desempenham papéis fundamentais, na comunidade de terreiro, que resultam em profundo impacto social, pois são elas que agregam a maior parte da população negra em seus locais de culto, não apenas com a preocupação da prática das crenças espirituais, mas também como uma proposta de busca da identidade, enfrentamento do racismo e fortalecimento para a resistência contra todo tipo de opressão hegemônica.

Essas mulheres buscam a consolidação da liberdade de culto declarada em lei brasileira, já que essa formação religiosa por elas vivenciada foge do padrão hegemônico e, por isso, elas sofrem forte reprimenda da sociedade. As mulheres negras de terreiro compreendem a mais pura expressão de seriedade e compromisso com a população negra, assim como de intervenção intelectual estratégica para o empoderamento dos adeptos das religiões de matriz africana, pois, inseridas em um sistema político de imposição de cultura e de religião portuguesa, manter vivas as tradições e os cultos demonizados com vivacidade é pensar politicamente a contra-hegomonia intelectual do seu tempo e fazer história com seus atos; é produzir, portanto, intelectualidade.

Destarte, diante do exposto é evidente que dentro de um sistema sociopolítico em que a mulher, especialmente a negra, é concebida na sociedade por uma ideologia sexista e racista, tem eliminada a possibilidade de ser reconhe-

II Sacerdotisa e chefe de um terreiro de candomblé, conhecida também como Mãe de Santo. É a zeladora do culto dos orixás, divindades cultuadas em muitas religiões de matriz africana. 
cida como intelectual e tem reservado um lugar em que é sinônimo de símbolo sexual, destituída de erudição e determinada à exclusiva capacidade do trabalho doméstico para os brancos, as mulheres negras acima citadas ascendem na contramão dessa ideologia e desse espaço que lhes é perversamente reservado e, ao resistir a um sistema racista e sexista, contribuem para uma nova compreensão do mundo, abalando os pilares da estrutura política.

\section{A luta pela conquista da legitimação da intelectualidade: 0 direito à memória}

Reconhecendo a contribuição intelectual dessas mulheres negras e a existência de uma negação a essa contribuição, permitimo-nos também realizar uma reflexão sobre a necessidade do direito à memória. Mesmo não pertencendo à ordem positiva do Estado, o direito à memória é inalienável, pois se refere à identidade cultural de um povo e procede da própria natureza humana. As construções intelectuais de um sujeito que promove transformações em qualquer esfera da sociedade, por meio de atividades que gerem tanto cultura como história, refazem a política. Enfim, qualquer que seja a atividade empreendida por um cidadão que tenha impacto significativo na sociedade, transformando-a em algum aspecto pelo labor intelectual, a memória dessa contribuição, dessa atividade, deve ser conservada e protegida.

Podemos compreender cultura como uma dimensão do processo social e, segundo José Luís dos Santos (I983, p. 80), não podemos discutir cultura ignorando as relações de poder dentro de uma sociedade ou entre sociedades. E, nesse cenário, onde a cultura e a intelectualidade são dominadas por um grupo hegemônico, discutir o direito à memória cultural passa inevitavelmente pela reflexão das relações de poder. Segundo Marilena Chauí (2000, p. I62), "a memória cultural é a experiência que permite a um grupo social consolidar suas tradições por meio de símbolos, objetos e valores que se transmite de geração a geração até o ponto de constituir verdadeiros 'sinais' identificatórios". Podemos inferir que essa memória, sendo evidenciada em registros, serve de referencial para a construção da identidade de um ou mais indivíduos e serve como ferramenta para possibilitar cidadania.

No texto intitulado "Intelectuais negras", bell hooks (I995) fala da dificuldade de as estudantes afro-americanas citarem os nomes de negras intelectuais, expressando assim o desconhecimento de suas alunas sobre as pensadoras críticas negras. Esse problema de "memória" não é exclusivo das afro-americanas; no Brasil, podemos detectar o mesmo problema. 
Nos livros de literatura, por exemplo nos de autoria de Monteiro Lobato, de que maneira os personagens negros são apresentados? A única mulher negra da história fictícia é a serviçal chamada de Tia Anastácia, dedicada à culinária e às demais tarefas domésticas, sempre submissa à sua senhora Dona Benta ${ }^{12}$. Essa estigmatização apaga, nega, faz desaparecer todo o leque de referências de mulheres negras que traçaram caminhos na cultura, na arte, na história, na política, ou seja, no trabalho intelectual. Partindo dessa premissa é que se fazem necessários a segurança e os registros das obras, da vida e do pensamento - com o zelo dado aos bens culturais - de mulheres como Inaldete Pinheiro, Carolina Maria de Jesus, Vera Baroni, Maria Madelena Correia do Nascimento, Lia de Itamaracá, Dona Glorinha, Dona Montinha, Rainha Mariú, Rainha Dona Santa, as Yalorixás e várias outras intelectuais e pensadoras críticas negras que estão inseridas na periferia e/ou nas academias pernambucanas. Pois esse registro, a segurança do direito à memória e a preservação desses bens culturais são possibilidades de reconstrução social, de identidade, de autoestima, de reconhecimento da história do povo negro e servirão como lastro cultural para as próximas gerações de meninas e mulheres negras no Brasil.

Contudo, as dificuldades de reconhecimento do direito à memória, transcendem os limites de uma problemática estritamente jurídica,e recaem principalmente como problema político e ideológico. Reconhecer um direito cultural, que se constitui também em reconhecer o direito à memória, implica reconhecer a identidade coletiva de um grupo, legitimar sua relevante contribuição intelectual, afirmar suas capacidades e seu pertencimento a uma comunidade. Esse entendimento viabiliza a compreensão do motivo pelo qual as intelectuais negras caem no esquecimento da população, pois estão inseridas em uma sociedade estruturada no racismo e no sexismo que faz forte manipulação ideológica para a invisibilidade delas. A não preservação da memória conduz à perda do passado e de identidades, que terá como consequência a produção de uma próxima geração de indivíduos alienados. Portanto, é de suma relevância a ampliação das discussões do reconhecimento do direito à memória, pois ele se constitui como ferramenta de visibilização positiva do protagonismo de intelectuais orgânicos - a exemplo das citadas mulheres negras - e, por conseguinte, um mecanismo de enfrentamento do racismo e do sexismo que insiste na negação da contribuição das mulheres negras em trabalhos intelectuais de grande relevância na construção da sociedade brasileira.

12 A obra de Monteiro Lobato citada foi utilizada de modo exemplificativo: trata-se de uma série de volumes, escrita pelo autor, intitulada Sítio do pica-pau amarelo. 


\section{v. Considerações finais}

É pelo prisma do conceito de intelectuais orgânicos de Gramsci que temos a possibilidade de enxergar as mulheres negras e todo o leque de produção intelectual desenvolvida por elas.

Devido a toda a conjuntura ideológica racista e sexista da sociedade, conhecemos muito pouco da história de nossas intelectuais mulheres negras, esvaziada pela desimportância atribuída às suas trajetórias e, em consequência, às suas produções. Contudo, essas mesmas mulheres negras, ainda que invisibilizadas pela história, enfrentaram o silêncio do racismo e do sexismo promovendo a formação de uma nova consciência sociopolítica e mantiveram as tradições, resgatando a memória de um povo. O racismo e o sexismo são os agentes ativos do processo da interdição e da negação da trajetória e das obras de nossas intelectuais negras. A interdição de exaltar a intelectualidade das mulheres negras ocorre exatamente pela negação delas como tal, pela fraude da trajetória da população negra, romantizando um período escravista pelas teorias do mito da democracia racial até os dias de hoje.

As produções intelectuais das mulheres negras aqui rememoradas constituem expressões de compromisso, o fortalecimento da identidade e o desenvolvimento cultural de um povo, haja vista que a preservação da memória é condição indispensável para a existência e continuidade da história de um povo.

Essa manipulação hegemônica de quem pode ser e quem não pode ser considerado um intelectual, com pré-requisitos a serem atendidos para ocupar esse lugar, afasta a população negra de receber tal status, especialmente as mulheres negras. Por fim, ponderamos acerca da garantia e do reconhecimento do direito à memória como importante ação no enfrentamento do racismo que nega as contribuições de mulheres negras intelectuais. Entretanto, as mulheres citadas são uma singela demonstração de que o espaço sociocultural deve ser ocupado também por elas, tendo em vista todo o labor intelectual e as contribuições das transformações sociais por elas promovidas. Garantir o direito à memória dessas mulheres é respeitar o passado e salvaguardar o futuro de uma população.

\section{Referências}

CHAUÍ, Marilena. Convite à filosofia. São Paulo: Ática, 2000.

GRAMSCI, Antonio. Os intelectuais e a organização da cultura. Rio de Janeiro: Civilização Brasileira, I982. 
JESUS, Carolina Maria de. Quarto de despejo: diário de uma favelada. São Paulo: Ática, 2006.

MUNANGA, Kabengele. Negritude: usos e sentidos. São. Paulo: Autêntica, 2009.

NASCIMENTO, Elisa Larkin. Guerreiras da natureza: mulher negra, religiosidade e ambiente. São Paulo: Selo Negro, 2008.

NASCIMENTO, Elisa Larkin. O sortilégio da cor: identidade, raça e gênero no Brasil. São Paulo: Summus, 2003.

SANTOS, José Luiz. dos. O que écultura? São Paulo: Brasiliense, I997.

FERNANDES, José Ricardo Oria. Educação patrimonial e cidadania: uma proposta alternativa para o ensino de história. Disponível em: <www.anpuh.org/arquivo/download? ID_ARQUIVO=3738>. Acesso em: 4 maio 2016.

HOOKS, Bell. Intelectuais negras. Estudos Feministas, v. 3, n. 2. Portal de Periódicos UFSC, I995. Disponível em: <https://periodicos.ufsc.br/index.php/ref/ article/view/I6465/I5035>. Acesso em: 23 fev. 2016.

HOOKS, Bell. Alisando o nosso cabelo. Pele negra. I8 maio 2009. Publicado originalmente em: Revista Gazeta de Cuba - Unión de escritores y Artista de Cuba, jan./fev.2005. Tradução do espanhol: Lia Maria dos Santos. Disponível em: <http://pelenegra.blogspot.com/2009/05/alisando-o-nosso-cabelo.html>. Acesso em: 23 fev. 2016.

LIMA, Ivaldo Marciano de França. Entre Pernambuco e a África: história dos maracatus-nação do Recife e a espetacularização da cultura popular. Rio de Janeiro, 20IO. Disponível em: 〈http://www.historia.uff.br/stricto/td/I250.pdf $>$. Acesso em: 23 fev. 2016.

MUNANGA, Kabengele. Superando racismo na escola. Brasília, 2005. Disponível em: $<$ http://www.dominiopublico.gov.br/pesquisa/DetalheObraForm.do?select_ action=\&co_obra=I0332I $>$. Acesso em: 20 abr. 2016.

SANTOS, Jean Carlos Ferreira. Saber, beleza e arte em Carolina Maria de Jesus. Revista Palmares: cultura afro-brasileira. I ed. n. 2, 2005. Disponível em: <http://www.palmares.gov.br/revista/>. Acesso em: I7 maio 2016.

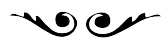

Jacqueline Martins é granduada em Direito pela Faculdade de Olinda em 2016.

jacque.martinsalves@hotmail.com 